\title{
Avaliação, cognição e poder
}

Vera Lúcia Menezes de Oliveira e Paiva

UFMG/CNPq

Liliane Assis Sade

Doutoranda/UFMG

A avaliação reflete a concepção de ensino adotada pelo professor e, dependendo de como esse processo é entendido, pode funcionar como mera checagem de um resultado ou focalizar o processo de ensino/aprendizagem. Pode, também, ser usada como um instrumento de poder que demarca a assimetria dos participantes no ato educativo. Tomando a concepção de poder em Foucault (1989) e associando-a aos contextos de avaliação de acordo com Perrenoud (1999) e Barlow (2006), este artigo procura analisar algumas memórias de aprendizes a partir de uma leitura das pesquisas realizadas na área da Cognição, com base, principalmente, nos trabalhos de Potter (1995), Sutton (2004), Hampson e Morris (1996), e interpretá-las à luz dos novos paradigmas cognitivos que consideram o indivíduo como um ser situado em uma narrativa histórica de práticas sociais, nas quais as relações de poder estão implícitas no ato comunicativo e nas inter-relações pedagógicas.

The process of evaluation reflects the concept adopted by teachers towards teaching. Depending on how they understand this process, the evaluation can only check some learning results or focus the process of teaching/learning, or yet, be used as an instrument of power that frames the asymmetry among the participants in the educative act. Taking the concept of power in Foucault (1989) and applying it to evaluation contexts according to Perrenoud (1999) and Barlow (2006), this paper analyzes some learners memories, having as support researches developed in Cognition, mainly the works of Potter (1995), Sutton (2004), Hampson \& Morris (1996), interpreting them under the theoretical assumptions of the new cognitive paradigms that consider the self located in a particular social-historical narrative, in which power relations are implicit in the communicative act and in pedagogical practices.

\section{Introdução}

Perrenoud (1999, p. 9) afirma que a avaliação não é uma tortura medieval. "É uma invenção mais tardia, nascida com os colégios por volta do século XVII e tornada indissociável do ensino de massa que conhecemos desde o século XIX, com a escolaridade obrigatória”. Ele acrescenta que 
a avaliação "inflama necessariamente as paixões, já que estigmatiza a ignorância de alguns para melhor celebrar a excelência de outros", e lembra que para alguns adultos ela evoca experiências gratificantes e para outros uma seqüência de humilhações. Colocaríamos entre aspas tanto a ignorância como a excelência, pois em muitas experiências, tanto uma como a outra podem ser produto da sorte (ex. sorteio de pontos em prova oral), da cola, do subjetivismo do professor, ou ainda da valorização do produto em detrimento do processo, como discutiremos mais à frente.

\section{Concepções de avaliação}

Ao falar de avaliação, é importante que se tenha em mente qual é o conceito adotado e quais são seus objetivos. O conceito de avaliação está intimamente vinculado ao de ensino adotado pelo professor ou pela instituição escolar. A forma como essa questão é concebida no contexto educacional vai influir no tipo de prova e na maneira como o conteúdo será checado.

Na concepção mais tradicional, o ensino está associado à mera transmissão de conteúdo; o professor é visto como depositário e o aluno como receptor do conhecimento; e o objetivo da avaliação é a mera conferência da matéria ensinada (ou "depositada no aluno"). Nessa perspectiva, a educação é vista como resultado e a avaliação como um importante sinalizador desse produto.

Recentemente, com a mudança de foco ocorrida na educação, que passou a incluir o aluno no eixo central da pedagogia, a concepção tradicional de ensino deu lugar à expressão ensino / aprendizagem, evocando, assim, a participação do aluno como agente ativo do seu aprendizado. A noção de educação como resultado também é modificada e passa a ser vista como processo. Quando se muda o foco de ensino como busca de um resultado para ensino/aprendizagem como processo, os objetivos da avaliação também mudam e esta passa a ser uma fonte importante de feedback para o professor, sinalizando o percurso percorrido pelos alunos ao longo do processo; um instrumento para averiguar o nível de proficiência da turma e orientar os futuros planejamentos pedagógicos; e, finalmente, uma forma de motivar e incentivar os alunos, mostrando a eles mesmos do que são capazes e os pontos que ainda devem ser trabalhados. 
Além desses dois enfoques da educação, infelizmente, vale mencionar ainda que há um terceiro no qual a educação é vista como exercício de poder, em que, tomando-se o conceito de Bourdieu (1977), o professor é o detentor do capital cultural e os alunos meros subordinados, submetidos às decisões e desejos dos docentes e da instituição escolar. Nesta perspectiva, a avaliação passa a ser usada como um instrumento para a punição ou para assegurar a manutenção do poder.

\section{Avaliação e poder}

Sempre que conversamos com alguém sobre suas memórias da vida escolar, não raro surgem histórias sobre avaliação, ora relatando abusos de poder e humilhações e ora descrevendo mecanismos de resistência para burlar e sobreviver ao sistema.

Vasculhando nossa memória e lembrando-nos de situações vivenciadas por nós mesmas, por nossos filhos, parentes e amigos, agregamos a nossas reflexões sobre avaliação alguns registros dessas memórias:

Século 20, década de 50

(a) Um aluno que não soube fazer uma leitura no primeiro dia de aula do curso primário foi colocado na cadeira dos burros.

(b) Uma aluna, na quarta série do antigo curso primário, com excelente rendimento escolar, é colocada em uma fila de alunos denominada fila dos atrasados, porque conversava muito durante as aulas.

Século 20, década de 60

(c) Determinado grupo de alunos de uma escola vasculha o lixo em busca das matrizes de provas usadas nos mimeógrafos e juntos conseguem tirar as maiores notas em algumas disciplinas.

Século 20, década de 70

(d) Um aluno universitário faz a sua prova e a da colega ausente, mas a última, apesar de ausente, consegue nota maior.

Século 20, década de 80

(e) Uma professora de matemática retira um ponto do total da nota de uma aluna porque a mesma não lhe devolvera uma das avaliações com a assinatura dos pais. 
(f) Um aluno é reprovado no segundo ano do, então, ensino primário. A professora comenta com os pais: "ele até sabe, mas não coloca na prova”.

Século 20, década de 90

(g) Um professor universitário comenta com seus colegas: eles vão ver a prova que vou dar a eles.

Século 21, 2005

(h) Pós-graduandos são submetidos a uma argüição oral, com sorteio de pontos correspondendo a dez teorias diferentes de uma determinada área, sem apoio de textos ou anotações. Uma doutoranda que dominava 7 dessas teorias foi solicitada a discorrer sobre uma que não dominava bem, tendo de dar exemplos de aplicação de uma teoria com a qual nunca trabalhou. Sua nota, um pouco acima da média, foi inferior às dos colegas que já estavam inseridos na área.

Machado, ${ }^{1}$ in Foucault (1989a, p. xiv), na introdução de Microfísica do Poder, afirma que "[R]igorosamente falando, o poder não existe; existem sim práticas ou relações de poder. O que se exige dizer que o poder é algo que se exerce, que se efetua, que funciona." O poder para Foucault "não é um objeto, uma coisa, mas uma relação".

Em uma profissão como a dos professores, onde não existe um código de ética como acontece com a maioria das profissões, como bem lembra Maria da Graça Paiva (comunicação pessoal), as relações de poder que o sistema escolar e, conseqüentemente, o professor estabelecem com seus alunos deixam os últimos em uma situação de total desamparo, sujeitos a humilhações, como em (a) e (b), abuso de poder, como em (e), (f) e (g), e exageros, como em (h), pois as decisões são unilaterais e não encontram respaldo em nenhuma teoria educacional. Em todos esses relatos a avaliação não esteve a serviço da aprendizagem, mas do exercício do poder.

A atribuição de notas é outro momento de exercício de poder. Os professores são classificados pelos alunos como "bons de notas" ou

\footnotetext{
${ }^{1}$ MACHADO, R. Introdução, por uma genealogia do poder. In: FOUCAULT, M. Microfísica do poder. 8. ed. Org. e Trad. Roberto Machado. Rio de Janeiro: Edições Graal, 1989.
} 
"ruins de notas", bonzinhos e durões. Há também os que se recusam a reconhecer a excelência de seus alunos e nunca lhes atribuem a nota máxima, como forma de marcar a distância entre alunos e professor, como bem lembra Barlow (2006, p. 40). Barlow enfatiza que "[a]o que parece, o prazer de dar nota está, antes de tudo, em saborear um certo poder. Por definição, pronunciar um julgamento de valor é - pelo menos implicitamente - considerar-se como detentor da norma do bom, do verdadeiro, etc." Como "todo saber assegura o exercício de um poder" (p.35), Machado, interpretando o texto de Foucault (1989a, p. xxii), diz que o professor preserva seu poder ao não compartilhar o espaço da excelência com seus alunos.

Prieto e Gutierrez (1991) lembram que a avaliação é poder. Esse poder está concentrado, freqüentemente, em apenas duas mãos - a de um professor que pode decidir o que, como e quando avaliar, mesmo que suas escolhas não sejam as melhores para o aprendiz. Em (a) e (b), temos a manifestação de abuso de poder que contribuiu para abaixar a auto-estima e humilhar as crianças. O primeiro ficou um ano sem freqüentar a escola, sendo alfabetizado em casa, e a segunda ficou o resto do ano letivo na fila dos alunos fracassados. Como ela era bem sucedida, o episódio só serviu como humilhação, mas é possível imaginar como ficava a auto-estima de seus colegas cujas avaliações os mantinham na fila dos atrasados. Os resultados das provas não eram usados a favor daquelas crianças com ações pedagógicas que os ajudassem a melhorar seus desempenhos. A professora apenas usava seu poder de discriminar e humilhar seus alunos. Como explica Barlow (2006, p. 153),

por alguns ritos tradicionais, a avaliação escolar é um ato de segregação. Ela consistia (e consiste ainda, aqui ou ali) em separar os melhores sujeitos, tornando visível essa elite escolar. Essa segregação, como vimos, manifesta-se de diferentes maneiras: seja pela proclamação pública dos resultados (notas cifradas, classificação por ordem de mérito, "quadro de honra", etc.); seja por sinais distintivos (cruzes, fitas, etc.); seja, enfim, concedendo nas salas de aula "lugares de honra" para os melhores alunos.

No caso de (f), o aluno, por ser mais lento que os colegas, não conseguia terminar as provas dentro do tempo alocado. Por não conseguir acompanhar o ritual de avaliação, dentro do tempo, foi reprovado, apesar de a professora ter a consciência de que ele sabia os conteúdos. Nesse caso, o aprendiz é separado, segregado, por ter um ritmo diferente dos colegas. 
A avaliação, muitas vezes, é um mero instrumento disciplinador e controlador, um pretexto para mostrar aos alunos quem tem poder, como em (e), em que vemos uma professora arbitrária que usa a nota para fins alheios à avaliação da aprendizagem e em (f), em que o professor verbaliza sua intenção de usar a prova como instrumento de vingança contra o comportamento dos alunos que o deixaram irritado.

Pontes (2001, p.32) argumenta que

a relação de poder existente entre o professor e o aluno é complexa, pois em uma turma que é avaliada através de teste / prova, o resultado da mesma é sempre visto como fracasso ou êxito individual do aluno. É como se o processo pedagógico fosse perfeito e somente o aluno culpado de dar errado o seu desenvolvimento, deixando todo o resto - professor, livro didático, currículo etc... acima de qualquer suspeita. (...)

Assim o professor tem o poder, é ele quem diz quem é nota "dez ou zero", ou quem é promovido à série seguinte ou não, são rituais que fazem parte do universo educacional, logo a criança ou adolescente é coagido sem poder reagir, pois é ele quem é avaliado e não o sistema...

No entanto, como podemos comprovar em (c) e (d), os próprios alunos, muitas vezes, burlam o sistema. Em (c), a ação dos alunos, efetivamente, levou a alguma aprendizagem, pois os mesmos se preparavam para responder às questões às quais eles tinham acesso privilegiado. Esses casos reforçam a aleatoriedade sempre presente nas avaliações, seja por interveniência do acaso, como em (h), ou de ações de burla do sistema por parte do aluno, como em (c) e (d).

Tanto em (c) como em (d) temos uma resistência à ordem imposta, quando os alunos minam a estrutura da avaliação em evidente guerra ao poder. Como afirma Perrenoud (1999, p.165),

ninguém fica indiferente ao julgamento de seus conhecimentos ou competências. O primeiro movimento de cada um é o de tentar mostrar suas qualidades, portanto, é o de se defender contra a manifestação de suas lacunas e de seus limites. Quem avalia sente-se honrado, em contrapartida, por não se deixar enganar, por razões muito honrosas e outras mais confusas. Portanto, é normal que todo relatório de avaliação tenha uma dimensão conflitual e se pareça, em parte, com o jogo de gato e rato.

Como a avaliação, geralmente, está a serviço apenas da nota e não de um diagnóstico que permita a realimentação do sistema de ensino/ 
aprendizagem, esses alunos burlam o sistema para garantir para si e para seus pares a sobrevivência dentro dessa estrutura repressora e punitiva da escola.

\section{Avaliação e cognição}

Para desenvolver as considerações que julgamos pertinentes, é importante salientar que toda avaliação, seja qual for o tipo, requer um esforço cognitivo por parte de quem a ela se submete. Sendo assim, podemos dizer que a avaliação está intimamente relacionada à cognição e, de acordo com o paradigma cognitivo adotado, pode passar de uma simples conferência do produto de um ensino para ter um enfoque no processo ou mesmo se transformar em exercício de poder. Devido à relevância dessa questão, esta seção será dedicada à relação entre cognição e avaliação.

No decorrer do desenvolvimento do pensamento científico na área da Cognição, pôde-se constatar a formação de três grandes linhas de pesquisa que tentam explicar a cognição humana: Cognitivismo, Conexionismo e Corporeidade, das quais duas delas (Cognitivismo e Conexionismo) tentam explicar a cognição humana associando-a a diferentes metáforas computacionais.

O Cognitivismo está essencialmente fundamentado nos trabalhos de Fodor (1983), Pinker (1989) e Chomsky (1965). Para Fodor (1998, p. 127-128), a mente é modular, o que implica especificidade de domínio; é encapsulada e as informações e operações de cada módulo são geneticamente pré-organizadas. Há a idéia de um processador central que recebe as informações dos módulos e as transforma em output. A memória está associada à metáfora do armazenamento e estocagem de informações. A metáfora da representação é a do espelho, ou seja, as representações mentais são o reflexo do mundo exterior.

O segundo paradigma da cognição é o Conexionismo. Esse novo paradigma pode ser associado aos nomes de David E. Rumelhart e James L. McClelland (1986) e aos de outros teóricos que participaram do grupo de pesquisa que desenvolveu um novo modelo cognitivo denominado "Processamento de Distribuição Paralela". Esse novo modelo adota a metáfora computacional das redes conectadas e se contrapõe, em diversos aspectos, ao modelo cognitivista tradicional. Nesse modelo, a 
cognição não é resultado de um processamento central, mas está distribuída em redes interconectadas de neurônios. As unidades de rede são acionadas conforme o input externo por meio de pesos - influências excitatórias e inibitórias. As representações mentais são construídas a partir das interconexões neurais que são criadas em decorrência dos impulsos excitatórios. Sendo assim, no que tange o sistema de representações, a metáfora do espelho é substituída pelo conceito de emergência. As conexões neurais criam generalizações dos inputs recebidos. Quando um input não se encaixa nas generalizações já criadas, as redes se calibram para ajustar a nova informação.

O terceiro paradigma da Cognição é o da Corporeidade. Esse paradigma, que está associado aos nomes de Maturana e Varela (1980); Varela, Thompson e Rosch (1991); Johnson e Rohrer (2005), desfaz a dualidade corpo e mente e advoga que a cognição ocorre em todo o corpo. O desenvolvimento cognitivo do indivíduo ocorre a partir da interação interna e externa do organismo. ${ }^{2} \mathrm{O}$ fator social é essencial para esse desenvolvimento - o organismo, para se proteger e se manter, desenvolve mecanismos de adaptação ao meio e são esses mecanismos que concorrem para o processo da cognição. Esse terceiro paradigma desconsidera a noção de representação mental e introduz a noção de esquemas imagéticos que surgem a partir da experiência física do corpo com o meio ambiente. Os esquemas imagéticos são definidos por Johnson e Rohrer (2005, p. 21-22) como padrões recorrentes de experiência sensório-motora que nos habilitam a entender o mundo e agir sobre ele da forma como o fazemos. A formação de conceitos e, em um nível mais aprofundado, a própria linguagem, é um processo decorrente dessa experiência corpórea.

A partir dessa breve descrição dos três paradigmas da cognição, vamos traçar algumas considerações sobre aprendizagem e avaliação. Para tanto, nos remetemos ao conceito de memória e como ela é abordada nessas diferentes concepções de cognição.

\footnotetext{
${ }^{2}$ A interação externa não se limita ao contato com o ambiente imediato; a cultura e as experiências vividas são também responsáveis pelo desenvolvimento cognitivo.
} 


\subsection{A memória}

Neste trabalho entendemos memória de acordo com Sutton (2004), que a define como "um nome dado para um conjunto de capacidades cognitivas pelas quais os seres humanos, e talvez alguns animais, retêm informações e reconstroem suas experiências passadas, geralmente para as propostas presentes".

A definição de Sutton implica diversos aspectos que serão úteis para as reflexões que se seguem. Primeiramente, a relação entre avaliação e memória fica claramente estabelecida, uma vez que a avaliação, via de regra, irá checar a informação retida. Em segundo lugar, Sutton, ao esclarecer que a memória possibilita a reconstrução de experiências passadas para propósitos presentes, faz uma ligação entre a narrativa histórica do indivíduo e a inserção do sujeito em um contexto social determinado. Dessa forma, o autor evoca a noção de memória vinculada à dialética da formação do eu individual e social, ou seja, vincula a memória do indivíduo à sua experiência de vida, que o distingue dos outros indivíduos, ao mesmo tempo em que o torna socialmente construído.

Voltemos aos paradigmas. No Cognitivismo, a memória é tida como um arquivo que pode ser acessado para obter informações já estocadas. Sutton (2004) explica que o âmago da visão filosófica da memória como representação consiste em se acreditar que um traço adquirido na experiência passada, de alguma forma, "representa" aquela experiência, ou carrega informação sobre ela. Por essa perspectiva, podese inferir que uma informação armazenada pode ser recuperada, exatamente como foi estocada por qualquer indivíduo. Sendo assim, para as questões de avaliação, poderíamos dizer que o conteúdo apresentado pelo professor poderia ser armazenado e re-acessado pelo aluno quando necessário, na hora da testagem. Essa é a visão do ensino como resultado. Uma vez apresentado o conteúdo, todos os alunos, igualmente, poderiam re-acessar essa informação, já que o conteúdo foi apresentado para todos e a avaliação é apenas a solicitação de re-acesso, ou seja, a verificação daquilo que realmente foi armazenado. Essa visão tradicional e simplista de avaliação é, no entanto, questionada quando se muda o paradigma de cognição.

O Conexionismo desconsidera a memória como representação e passa a entendê-la como reconstrução. Vários tipos de reorganização 
acontecem à informação retida no cérebro em um mesmo período. A memória não é algo que é estocado de forma estática, mas é dinâmica e está constantemente em processo. Sutton (2004) explica que, no Conexionismo, lembrar significa a reativação temporária de um padrão particular entre as unidades da rede neural. Essa reconstrução é possível devido às influências do input atual e a história da rede, sendo que essa história está sedimentada nos pesos das conexões entre as unidades já padronizadas. Traços de memória não são armazenados estaticamente e, sim, estão sobrepostos no mesmo conjunto de pesos. Nesses modelos, os mesmos veículos ou recursos são usados para carregar diferentes conteúdos. Cada vez que um estímulo é processado, ele faz surgir um traço diferente de memória. Um mesmo estímulo causa diferentes lembranças em indivíduos diferentes de acordo com os padrões já construídos pelas redes neurais, em virtude das experiências individuais. Devido a isso, Sutton (2004) propõe que lembrança, no conexionismo, é "um processo inferencial, construtivo e não reprodutivo".

A Corporeidade propõe que a cognição não está centrada apenas na mente, mas distribuída em todo o corpo. Os defensores dessa corrente teórica propõem que não existe memória como representação. O que existem são esquemas imagéticos. Johnson e Rohrer (2005, p. 21) explicam esses esquemas da seguinte forma: os indivíduos estão sujeitos a forças que os movem, transformam os seus estados corpóreos e condicionam suas ações, e essas forças têm padrões e qualidades características. Sem esses padrões, e sem mapas neurais de tais padrões, cada momento de nossa experiência seria caótico, como se tivéssemos de fazer sentido de nosso mundo a cada vez que uma nova experiência se apresentasse. Os esquemas de imagem são precisamente esses padrões recorrentes de experiência sensório-motor pelos quais os indivíduos entendem e agem no mundo de acordo com suas propostas. Sutton (2004) argumenta que a memória externa, ou seja, as interações com o ambiente social e cultural adquiridas via experiência interagem com as interações internas - e ambas são acionadas para significar as situações presentes.

Quando passamos do paradigma Cognitivista para os novos paradigmas, sejam eles o Conexionismo ou a Corporeidade, que tomam o indivíduo como um ser inserido em um momento histórico e um contexto social específico, muda-se também a concepção de cognição, 
o conceito de memória e essas mudanças acarretam, de forma indireta, uma nova postura frente a outras questões, que no nosso caso, implica uma nova postura frente à avaliação. Pode-se argumentar que ao mudar de paradigma, mudamos o enfoque da avaliação de resultado para processo e minimizamos a imposição do poder do professor.

Para constatar a relevância dessa mudança de paradigma no entendimento da avaliação, citaremos algumas pesquisas sobre memória realizadas dentro do Cognitivismo e as interpretaremos sob a luz dos novos paradigmas, a saber, o Conexionismo e a Corporeidade e, a partir daí, desenvolveremos nossas reflexões sobre avaliação.

Potter (1990) apresenta uma série de estudos realizados sobre a memória. Para as reflexões sobre avaliação que faremos, evidenciaremos alguns pontos que emergem dessas pesquisas e que embasam as reflexões que serão desenvolvidas.

1) Importância do significado em detrimento da forma - o estudo realizado por $\operatorname{Sachs}^{3}$ (1974), citado por Potter, demonstra que, ao ler um texto, as pessoas não se recordam da gramática utilizada na estruturação das frases, mas sim do significado do texto. A gramática utilizada é retida apenas na memória de trabalho, enquanto o significado é o que se retém na memória de longo prazo. Outros estudos mencionados pela autora, como os de Craik e Tulving ${ }^{4}$ (1975), Wiseman e Neisser ${ }^{5}$ (1974), Bower, Karlin e Dueck ${ }^{6}$ (1975), apontam para a maximização da facilidade de memorização de elementos textuais e não textuais, quando a memorização se faz pelo significado. Essa observação tem uma importante implicação pedagógica para o ensino e para a avaliação, principalmente em contextos de aprendizagem de segunda língua ou língua estrangeira. Ao se ensinar

\footnotetext{
3 SACHS, J. S. Memory in reading and listening to discourse. Memory and Cognition, v. 2, p. 95-100, 1974.

${ }^{4}$ CRAIK, F. I. M.; TULVING, E. Depth of processing and the retention of words in episodic memory. Journal of Experimental Psychology: general, v. 104, p. 268-294, 1975.

5 WISEMAN, S.; NEISSER, U. Perceptual organization as determinant of visual recognition memory. American Journal of Psychology, v. 87, p. 675-681, 1974. ${ }^{6}$ BOWER, G. H.; KARLIN, M. B.; DUECK, A. Comprehension and memory for pictures. Memory and Cognition, v. 3, p. 216-220, 1975.
} 
uma língua pelo método tradicional de ensino, visava-se à exaustiva explicação gramatical, sem que houvesse uma preocupação com as questões de significado. Muitos professores ainda hoje usam esse método no ensino, que, além de desmotivante, está fadado ao insucesso, uma vez que a avaliação nesse tipo de prática também será desenvolvida a partir da "cobrança" de formas gramaticais. A "cobrança" da gramática desvinculada do sentido é infrutífera, senão injusta, já que os estudos constatam que a capacidade de retenção de um conteúdo está relacionada ao significado e não à forma. Reter informações sobre a língua não implica ter competência comunicativa, ou seja, saber usar a língua em situações de comunicação autênticas.

2o - Repetição: importância da revisão - os estudos citados por Potter (1990) também demonstram que aquilo que é mais retido é o que é mais repetido. Essa conclusão parece óbvia para aqueles que já se inserem no meio pedagógico, mas, por mais incrível que possa parecer, ainda existem profissionais que se posicionam contra a revisão constante, ora porque acham que estão "perdendo tempo" ou porque consideram a repetição uma prática antiquada atribuída ao Behaviorismo. O resultado disso é novamente o insucesso. Um outro ponto relacionado à prática constante e abordado nas pesquisas é o caráter recente da informação - o que será mais lembrado é o que aconteceu mais recentemente (HAMPSON; MORRIS, 1996, p.167; POTTER, 1990, p.19). Com relação a isso, a prática constante ajuda a manter recente o conhecimento antigo.

$3^{\circ}$ Importância do enfoque nos interesses dos alunos - Potter (1990) argumenta que o que é mais lembrado é o que é mais importante e a importância está associada ao interesse do aluno, leitor, usuário de um produto, etc. A pesquisa realizada por Anderson e Pichert ${ }^{7}$ (1978) e citada por Potter demonstra que os leitores são capazes de reter mais aquilo que é significativo para eles. Sendo assim, quando um professor apresenta um conteúdo denso para seus alunos, denso no sentido de

\footnotetext{
${ }^{7}$ ANDERSON, R. C.; PICHERT, J. W. Recall of previously unrecallable information following a shift in perspective. Journal of verbal learning and verbal behavior, v. 17, p. 1-12, 1978.
} 
quantidade e profundidade, um esforço cognitivo maior é demandado. Cognitivamente falando, é impossível para os alunos se lembrarem de tudo o que foi apresentado. As pesquisas citadas por Potter demonstram que diante de um extenso conteúdo, os indivíduos não se lembram de detalhes, apenas do geral e do que foi significativo para eles. Mais uma vez, cabe aqui uma reflexão sobre a avaliação. Professores que sobrecarregam seus alunos com conteúdo demasiado, ao aplicarem a avaliação, devem se conscientizar de que detalhes não serão lembrados e sim aquilo que foi significativo para eles, e aquilo que é significativo para os indivíduos está associado às suas experiências vividas. Segundo Sutton (2004), "nossas capacidades para acessar, gerenciar e manipular corpos extensos de informações dependem das redes tecnológicas e culturais que construímos para nos ligarmos". Portanto, professores que não levam em consideração a inserção de seus alunos em suas narrativas de vida tendem a "cobrar" conteúdos como resultado e negligenciar o papel da avaliação como processo.

$4^{\circ}$ Atenção ao que é novo ou especial - de forma semelhante ao que foi argumentado no item 3 , Potter argumenta que uma outra razão pela qual lembramos mais de algumas idéias em detrimento de outras é porque nós damos às primeiras mais atenção na fase da estocagem. Essa atenção especial está vinculada ou a um interesse especial de nossa parte ou ao caráter novo ou surpreendente da informação. Mais uma vez, há a necessidade de se associar o ensino à experiência dos alunos.

$5^{\circ}$ Perspectiva adotada durante a fase de apreensão do conteúdo - essa é uma questão bastante interessante de ser observada. O estudo de Anderson e Pichert (1978), mencionado anteriormente, também demonstrou que conforme a perspectiva adotada pelo leitor na fase da leitura, este se lembra de determinados fatos e não de outros. Em sua pesquisa, os autores pediram a alunos universitários para lerem a descrição de uma casa, primeiro assumindo a posição de assaltantes interessados em saqueá-la e outra como pessoas interessadas em adquirila. Conforme a perspectiva adotada pelos leitores, alguns detalhes foram lembrados em detrimento de outros. A conclusão é que "o ponto de vista do leitor determinou a importância dispensada aos detalhes da história" (POTTER, 1990, p. 8). De forma similar, podemos desenvolver a analogia em relação à apresentação e posterior checagem de dado conteúdo. Ao apresentar a matéria, ou determinar o conteúdo, especialmente quando 
este é muito extenso, o professor pode optar por atribuir um nível de significância maior a determinados detalhes, de acordo com o que ele acha mais importante, ou seja, de acordo com sua perspectiva, com seu contexto e posicionamento social. Quando da checagem desse conteúdo, o professor espera que os alunos tenham igualmente priorizado os mesmos detalhes e lhes conferido a mesma importância. Quando a leitura de determinados alunos é a mesma do professor, ou seja, quando ambos adotam a mesma perspectiva, então a probabilidade de sucesso é maior. No entanto, nem todos os alunos compartilham de experiências e background semelhantes ao do professor e, devido a isso, podem fazer leituras divergentes, priorizando outros detalhes. Ao serem avaliados pela ótica do professor, eles são "podados" de sua própria ótica e seus resultados não são tão bons quanto dos alunos que adotaram a perspectiva do professor. No caso (f), o aluno foi reprovado porque "não conseguiu colocar na prova" aquilo que o professor esperava, ou queria. Será que poderíamos dizer, de forma justa, que esses alunos são menos competentes ou menos merecedores de uma nota ou conceito do que aqueles que tiveram sucesso? Será que o fracasso ocorrido não seria apenas uma questão de perspectivação? Afinal, parafraseando Potter (1990, p. 9), a memória não é apenas um videotape do acontecido, capaz de reproduzir um evento tal qual aconteceu, mas está "contaminada" por processos de percepção e pensamento que concorrem para que objetos sejam reconhecidos, cenas interpretadas e frases entendidas de acordo com o significado e grau de importância que o indivíduo devota a eles. E esse grau de importância está vinculado ao posicionamento histórico do indivíduo, ao caráter social de seu "eu", que possui objetivos determinados pelo local social em que se encontra e que o habilita a significar os eventos de acordo com sua perspectiva social. Vista por esse prisma, a avaliação assume um caráter subjetivo, uma vez que ela reflete uma perspectiva determinada e que exclui outras. O professor que não considera o background do aluno e desconsidera essa questão de perspectivação está exercendo seu poder e impondo o seu ponto de vista sobre o do aluno.

6o - Conhecimento prévio - Hampson e Morris (1996) levantam uma crítica aos estudos de memória desenvolvidos em laboratórios que

\footnotetext{
${ }^{8}$ Termo usado por Potter (1990, p. 9).
} 
desconsideram a inserção do indivíduo em uma narrativa histórica de vida. Para esses autores, esses estudos laboratoriais ignoram o conhecimento acumulado no passado, que será relevante na interpretação do que acontece no presente e na antecipação do futuro. Estudos realizados com base na vida real dos participantes oferecem oportunidades para que esse conhecimento prévio possa se manifestar na performance dos participantes. No paradigma tradicional da cognição, o conhecimento prévio é importante por facilitar o processamento do conhecimento novo na memória de curto prazo e seu futuro armazenamento na memória de longo prazo. Assim, quando o conhecimento novo pode ser associado a um conhecimento anterior, as chances de ser retido na memória de longo prazo são maiores.

Quando muda-se o paradigma e toma-se o ser humano inserido socialmente, a importância do conhecimento prévio assume uma dimensão ainda maior. O uso do conhecimento prévio, nesse caso, além de facilitar a retenção do conteúdo novo, vai, ainda, re-significá-lo. O sujeito, como ser inserido, não apreende um evento ou uma situação, ou no caso específico que estamos tratando, um novo conhecimento, tal como ele é, mas ele o reinterpreta de acordo com seu arsenal interno que foi socialmente construído.

Para teorizar sobre esse conhecimento prévio importante nas questões de memória, não podemos deixar de mencionar o trabalho de Bartlett (1932), que cunhou o termo schema, ou no plural, schemata, significando "molduras de conhecimento construídas através da experiência, que direcionam a interpretação da informação nova e controla nossas ações" (HAMPSON; MORRIS, 1996, p.154). Através dos esquemas, é possível entender como agir em dada situação e como interpretá-la.

A teoria dos esquemas foi explorada pelo paradigma conexionista nos anos 80. Essa relação é explicitada por Rumelhart et al. (1996),? citados por Sutton (2004) - "a história do processamento passado é 'armazenada'10 na matriz (durável, mas modificável) de pesos de conexão

\footnotetext{
${ }^{9}$ RUMELHART, D. E.; SMOLENSKY, P; McClELLAND, J.; HINTON, G. E. Schemata and Sequential thought processes in PDP models. In: McCLELLAND, J.; RUMELHART, D. E. (Ed.). Parallel Distributed Processing, v. 2. Cambridge: MIT Press, 1986. p. 7-57.

${ }^{10}$ Grifo do autor.
} 
das redes neurais e, logo, influencia (de forma holística e causal) o processamento em curso do input'.

A relevância desse conceito para as questões de memória é que, em qualquer situação, a experiência passada será a responsável por nos ajudar a significar as novas experiências, criando expectativas sobre a forma como os eventos irão ocorrer. Hampson e Morris (1996, p. 155) sugerem que os esquemas auxiliam a memória de quatro formas diferentes: (1) na seleção do que será retido e do que será esquecido; (2) na abstração da informação, permitindo a retenção do significado principal sem se ater a detalhes; (3) na interpretação da informação nova, uma vez que possibilita a utilização do conhecimento passado para auxiliar a compreensão da experiência atual; e (4) na integração e formação de uma única memória holística. Além disso, os autores propõem que, na fase da recuperação, os esquemas possibilitam uma moldura para a reconstrução das memórias.

Lembrar, para Bartlett, não é a re-excitação de inúmeros traços fixos, sem vida e fragmentários. É uma reconstrução imaginativa. Frawley (2006), com base em Bartlett, observa que as pessoas não se lembram do material apresentado diretamente, mas sim de um julgamento que teceram a respeito dele quando a ele tiveram acesso originalmente. A teoria de Bartlett embasou diversas pesquisas e uma característica observada nesses estudos é a de que os esquemas distinguem pessoas mais experientes e menos experientes em dada área. De forma geral, as pesquisas comprovam que os peritos, por já possuírem um esquema prévio da situação em questão, são capazes de lembrar mais do que os novatos. No entanto, apesar desse aspecto positivo, Hampson e Morris (1996, p. 159) observam que os esquemas prévios podem também causar interferências na apreensão da informação nova. Como os peritos em dada área já possuem conhecimento prévio na mesma, eles tendem a produzir resultados de memória baseados em seu conhecimento e não na lembrança exata da informação.

\section{A avaliação em língua estrangeira}

Qual a implicação desses estudos para a avaliação? A primeira resposta diz respeito à importância do conhecimento prévio por permitir um conhecimento não apenas do conteúdo, mas também do "como" 
o processo avaliativo irá ocorrer. Assim, poderíamos dizer que o processo de escolarização, ou usando o termo proposto por Kress (1989, p. 90), de socialização na escola, nada mais é do que fornecer, ou usando os termos de Kress, impor ao indivíduo o esquema que vai ajudá-lo ou condicionálo a atuar e significar o ato social de estudar. Alunos já habituados com esse esquema possuem melhores chances de sucesso e, portanto, o professor de línguas não deve negligenciar o fato de que os diferentes backgrounds de seus alunos podem interferir nas suas atuações:

professores que são encarregados de educar alunos cujos backgrounds culturais diferem de seu próprio background devem estar atentos a tais fatos. ... O clima para aquisição da língua em sala de aula pode ser consideravelmente 'perturbado' pelo que os alunos vêem como expectativas contraditórias para suas participações e, como resultado, certos obstáculos desnecessários se criam interferindo no caminho de seus sucessos (BROWN, 1994, p.176). ${ }^{11}$

O caso (a) demonstra como o aluno foi discriminado por ele não ter tido o background exigido pela professora. Como ele ainda não era alfabetizado, foi discriminado e humilhado e sua expectativa de aprender a ler foi minada pela atitude autoritária da professora.

Um outro aspecto relativo à importância do conhecimento prévio em contextos de avaliação deve ser mencionado. Conforme já foi visto anteriormente, na fase da retenção da informação nova, o conhecimento prévio possui um papel fundamental tanto na quantidade quanto na qualidade do que será retido. Esse conhecimento determina o que é ou não significativo para determinado indivíduo. Na fase da recuperação, isto é, quando indivíduo, ou no caso específico que estamos falando, quando o aluno for acessar sua memória em busca do conhecimento armazenado, quanto mais conhecimento prévio ele tiver sobre o tópico, ou seja, quanto mais expert ele for em dada área, maior a probabilidade de ele se lembrar de detalhes do conteúdo e, logo, de obter bons resultados

11 Tradução nossa de BROWN (1994, p.176): "Teachers who are charged with educating students whose cultural backgrounds differ from their own must of course attend to such factors ... The climate for effective classroom language acquisition may be considerably clouded by what students see as contradictory expectations for their participation, and as a result, certain unnecessary blocks stand in the way of their success". 
nos exames. Já quando o aluno é novato, a recuperação da informação será dificultada e o resultado comprometido. Hampson e Morris (1996, p. 168) argumentam que "alguns tipos de materiais são particularmente difíceis de aprender porque eles não possuem o significado inerente e as conexões com o conhecimento já existente, que normalmente tornam o aprendizado mais fácil".

Qualquer profissional que já atuou com ensino de idiomas sabe que é muito comum em salas de língua estrangeira, principalmente na escola ou universidade onde os alunos não são enquadrados de acordo com seu nível de proficiência, como nos cursos livres de idioma, encontrarmos alunos peritos na língua juntamente com outros que ainda estão iniciando seus estudos na mesma. O resultado da avaliação é óbvio, os alunos experts vão se sair muito melhor. Mais uma vez, colocase o questionamento: será que o aluno novato, que embora tenha tirado uma nota menor, mas que desenvolveu e conseguiu apreender mais do que antes, deveria ser avaliado da mesma forma que o expert que já domina o assunto? Avaliar o aluno e lhe atribuir notas ou conceitos sem considerar esse questionamento é considerar a avaliação apenas como resultado e não processo.

Um outro problema para a avaliação em língua estrangeira é o sistema educacional que empacota a aprendizagem em meses e bimestres. No ensino básico, geralmente, não é o professor que determina quando e como irá avaliar seus alunos, pois as escolas, geralmente, determinam que todos os professores devem avaliar os alunos através de $\mathrm{X}$ testes, aplicados na semana $\mathrm{Y}$, dentro do mês $\mathrm{Z}$. A escola não apenas determina a época da avaliação, mas, também, o tipo de instrumento. Em muitos casos, os testes de múltipla escolha ou provas abertas são obrigatórios, ficando descartada qualquer possibilidade de uma avaliação que adote formas alternativas como portfólios, ${ }^{12}$ diários de aprendizagem, amostras de interações por e-mail ou chat, ou desenvolvimento de projetos, privilegiando o processo e não o produto.

Outros obstáculos são os programas que precisam ser cumpridos e que não deixam espaço para que as avaliações funcionem como

\footnotetext{
${ }^{12}$ Portfólios são coleções de atividades desenvolvidas pelo aprendiz que indicam o progresso do aluno. Essas coleções são, geralmente, fruto de uma seleção do próprio aprendiz e documentam o que o estudante aprendeu.
} 
deveriam, ou seja, servindo de diagnóstico, de feedback, para que o professor possa ver o que ainda não está aprendido e rever com os alunos conteúdos, competências e habilidades. Os planejamentos são, geralmente, lineares, e não são previstos períodos de retorno a fases que não estão, ainda, consolidadas por um ou mais alunos.

Mas o problema mais grave está associado à natureza da aprendizagem de uma língua estrangeira. A aquisição de uma língua é um processo longo, não linear, e não pode ser medido em termos de meses e bimestres. O fato de se ensinar uma função comunicativa, ou uma regra gramatical, e de os alunos fazerem os exercícios e as atividades orientados pelo professor, não são garantia de que, dentro de determinado tempo, o aprendiz estará usando aquela função ou seguindo aquela regra. A aquisição de uma língua é um processo complexo e demanda tempo.

Vejamos, por exemplo, a aquisição dos morfemas. Os estudos sobre esse assunto (ver DULAY; BURT,1973; BAILEY; MADDEN; KRASHEN, 1974; PERKINS; LARSEN-FREEMAN, 1975) indicam que o morfema 's' da terceira pessoa do singular, por exemplo, é um dos últimos a ser adquirido, ao passo que o 's' do plural é adquirido mais cedo. Mesmo que o professor ensine a regra gramatical e o aluno saiba repeti-la, não depende da vontade do aprendiz adquirir o morfema 's' da terceira pessoa do singular dentro do espaço de um mês ou de um bimestre. Não é seu empenho pessoal que determinará a aquisição do morfema.

A aquisição não é um processo linear que acontece após a instrução formal e alguma prática, pois demanda tempo e oportunidades de uso e isso, naturalmente, foge ao controle do aprendiz, sendo injusta, portanto, sua penalização com notas baixas. O sistema educacional legisla sobre os períodos de aprendizagem sem levar em conta, os fatores cognitivos e as diferenças individuais.

Foucault (1989b, p. 160), ao discorrer sobre o poder disciplinar, compara-o a um modelo reduzido do tribunal. Segundo ele, "os castigos disciplinares devem respeitar uma ordem mista", ou seja, a observação de regulamentos e de processos naturais, como os estágios de aprendizagem. A respeito de escolas cristãs, diz ele:

as crianças das escolas cristãs nunca devem ser colocadas numa "lição" de que ainda não são capazes, pois estariam correndo o perigo de não poder aprender nada; entretanto a duração de cada estágio é fixada de maneira regulamentar e quem, no fim de três meses, não houver 
passado para a ordem superior, deve ser colocado, bem em evidência, no banco dos "ignorantes". A punição em regime disciplinar comporta uma dupla referência jurídico-natural.

É necessário, ainda, reconhecer que, durante esses estágios de aquisição, o aprendiz de língua testa hipóteses e que os erros "devem ser vistos como algo positivo e significativo, pois refletem as estratégias utilizadas pelos alunos para chegar à proficiência na língua-alvo" (FIGUEIREDO, 1997, p. 11).

Hubbard et al. (1990, p. 146) ressaltam que o uso da língua implica escolhas lexicais e gramaticais. Veja o que eles dizem sobre as escolhas dos alunos:

as escolhas que nossos alunos fazem na prática espontânea podem ser bastante reveladoras, pois indicam estágios na aprendizagem da língua. As escolhas negligenciadas são igualmente informativas. Alguns textos dos alunos exibem falta de ambição lingüística; seus autores estão preocupados em não se arriscar. Pode ser que haja mais mérito em tentar usar uma construção com um verbo frasal e errar do que confiar em uma alternativa já bem conhecida, mas que é segura. ${ }^{13}$

Como exemplo, eles citam as respostas de dois alunos em uma atividade de compreensão de textos. O primeiro opta por não correr risco e responde (1) He couldn't tolerate such bad behavioure o segundo tenta usar um phrasal verb e não é bem sucedido ao escrever (2) He couldn't put by with such bad behaviour. No entanto, temos em (2) uma evidência da dinamicidade do processo de aprendizagem do segundo aluno, indicando sua tentativa de usar algo novo, mas isso, geralmente, é penalizado pela escola.

A aprendizagem de uma língua é um processo complexo e os instrumentos de avaliação nem sempre conseguem captar de forma justa o desenvolvimento desse processo.

\footnotetext{
13 Tradução nossa de "The choices that our students make in free practice can be very revealing because they indicate stages in language learning. The neglected choices are just as informative. Some student compositions are lacking in linguistic ambition; their authors are preoccupied with 'playing safe'. There may be considerably more merit in attempting a phrasal verb construction and getting it wrong than in relying on a well-worn but safe alternative".
} 


\section{Conclusão}

A avaliação pode causar efeitos devastadores em nossos alunos. "Muitas vezes, um julgamento avaliativo, assim como uma foto instantânea, imortaliza o instante fugaz, expressando-o em termos definitivos - com o risco de desencorajar o aluno ao lhe negar um futuro (BARLOW, 2006, p. 130)", como foi o caso de (a) e (b), ou ainda (g).

Em (c), a posse da matriz da prova tornou o grupo de alunos experts no conteúdo que seria cobrado e garantiu a eles o sucesso no resultado. Em (d), a ajuda de um colega livrou a aluna da punição pela ausência no dia da prova. Nos dois casos, os outros alunos, que realmente se desenvolveram, que avançaram em seu processo de aprendizagem, talvez não tenham tido resultados tão favoráveis. Esses dois casos exemplificam como a nota foi usada de forma injusta, visando ao resultado e não ao processo.

Barlow (2006, p. 150) faz uma pergunta fundamental: "a que parte do aluno nos dirigimos quando o avaliamos: falamos à sua inteligência, à sua afetividade, às suas emoções, etc.?" Nós gostaríamos de acrescentar: falamos à sua memória? Recorremos à Sutton (2004) para sintetizar nossa conclusão sobre a questão da memória.

Se as memórias não são imagens mentais fixas ou itens discretos de qualquer natureza, permanentemente estocados na mente ou cérebro individual, então a memória individual relativamente instável pode necessitar de suporte de um scaffolding externo mais estável. A experiência nos sintoniza a determinadas informações, ou regularidades, ou artefatos, que podem ser explorados no presente. Isto não implica em negar a importância de nossa capacidade de, algumas vezes, nos lembrar de experiências que não estão retidas em algum meio externo, mas sugerir que nós apenas podemos entender profundamente tais capacidades se também levarmos em consideração nosso uso habitual dos recursos presentes nos quais ancoramos nossas versões do passado. ${ }^{14}$

\footnotetext{
${ }^{14}$ Tradução nossa de Sutton, 2004: "If memories are not fixed mental images or discrete items of any kind, permanently stored in the individual mind or brain, then the relatively unstable individual memory may need support from more stable external scaffolding. Experience attunes us to certain information or regularities or artifacts which we can exploit in the present. This is not to deny the importance of our capacity sometimes to remember experiences which are not retained in some external medium, but to suggest that we may only understand such capacities fully by attending also to our habitual uses of present resources on which to anchor our versions of the past".
} 
No caso de (h), a possibilidade de consultar anotações ou palavraschave poderia ter funcionado como um scaffolding externo. A experiência negativa da aluna em relação à avaliação não foi determinada pelo tipo de prova (escrita, oral, seminário, etc.), mas pela forma como o conteúdo foi exigido - de forma excessiva e cobrado em detalhes que não poderiam ser lembrados por todos os avaliados da mesma forma. Era, então, de se esperar que aqueles alunos que já possuíam mais conhecimentos prévios do assunto e tinham suas experiências "sintonizadas" àquelas informações obtivessem resultados melhores. Para os novatos, entretanto, a experiência totalmente nova e desvinculada de sua experiência anterior acarretou um fracasso relativo na avaliação. Se dos 10 quadros teóricos apresentados, os alunos tivessem tido a oportunidade de escolher um ou dois para explorarem de acordo com suas experiências e leituras prévias e seus interesses de pesquisa, então, muito provavelmente, os resultados seriam diferentes e todos, novatos ou não, poderiam ter tido as mesmas chances de sucesso.

Finalmente, nos caso de (e) e (g), tivemos manifestações de poder incompatíveis com o ato de educar. A avaliação foi utilizada como um instrumento disciplinar. "Na essência de todos os sistemas disciplinares, funciona um pequeno mecanismo penal", como lembra Foucault (1989b, p.159). Na escola, as micropenalidades pelos comportamentos indesejáveis se materializam, ainda hoje, através de avaliações. "Certos rituais avaliativos também consistem em "colocar no pelourinho" os maus alunos - e essa expressão não é pura metáfora” (Barlow, 2006, p.157), pois a cadeira dos burros, a fila dos atrasados deixaram marcas nas biografias de nossos personagens pelourinhos.

\section{Referências Bibliográficas}

ANDERSON, R. C.; PICHERT, J. W. Recall of previously unrecallable information following a shift in perspective. Journal of verbal learning and verbal behavior, v. 17, p. 1-12, 1978.

BARTLETT, F. C. Remembering: a study in experimental and social psychology. Cambridge: Cambridge University Press, 1932.

BAILEY, N.; MADDEN, C.; KRASHEN, S. Is there a "natural sequence" in adult second language learning? Language learning, v. 24, n.1, p. 235-243, 1974. 
BARLOW, M. Avaliação escolar; mitos e realidade. Trad. Fátima Murad. Porto Alegre: Artmed, 2006.

BOURDIEU, P. The economics of linguistic exchanges. Social Science Information, 16 (6), p. 645-68, 1977.

BOWER, G. H.; KARLIN, M. B.; DUECK, A. Comprehension and memory for pictures. Memory and Cognition, v. 3, p. 216-220, 1975.

BROWN, H. Douglas. Principles of Language Learning and Teaching. 3. ed. Englewood Cliffs: Prentice Hall Inc., 1994.

CHOMSKY, N. Aspects of the Theory of Syntax. Cambridge: MIT Press, 1965.

CRAIK, F. I. M.; TULVING, E. Depth of processing and the retention of words in episodic memory. Journal of Experimental Psychology: general, v. 104, p. 268-294, 1975.

DULAY, H.; BURT, M. Should we teach children syntax? Language learning, v. 23, n. 2, p. 245-258, 1973.

FIGUEIREDO, F. J. Q. Aprendendo com erros: uma perspectiva comunicativa de ensino de línguas. Goiânia: Editora UFG, 1997.

FODOR, J. A. The Modularity of Mind. Cambridge: MIT Press, 1983.

. In Critical Condition: Polemical Essays on Cognitive Science and the Philosophy of Mind. London: MIT Press, 1998.

FOUCAULT, M. Microfísica do poder. 8. ed. Org. e Trad. Roberto Machado. Rio de Janeiro: Edições Graal, 1989a.

FOUCAULT, M. Vigiar e punir. nascimento da prisão. Trad. Lígia M. Ponde Vassallo. Petrópolis: Vozes, 1989b.

FRAWLEY, O. Spenser's Trace: cultural memory and cognition. Disponível em: <http://www.dactyl.org/thought/Poetics-CogSci/frawley.htm>. Acesso em Março/2006.

HAMPSON, P. J.; MORRIS, P. E. Understanding Cognition, Oxford: Blackwell, 1996.

HUBBARD, P. et al. A training course for TEFL. Oxford: Oxford University Press, 1999.

JOHNSON, M.; ROHRER, T. We are live creatures: embodiment, American Pragmatism, and the Cognitive Organism. In: ZLATEV, J. et al. Body, Language, and Mind. v. I. Berlim: Mouton de Gruyter. 2005. 
KRESS, Gunther. Linguistic processes in sociocultural practice. Oxford: Oxford University Press, 1989.

MACHADO, R. Introdução, por uma genealogia do poder. In: FOUCAULT, M. Microfísica do poder. 8. ed. Org. e Trad. Roberto Machado. Rio de Janeiro: Edições Graal, 1989.

MATURANA, H. R.; VARELA, F. J. Autopoiesis and cognition: the organization of the living. Boston: Reidel, 1980.

PERKINS, K.; LARSEN-FREEMAN, D. The effect of formal language instruction on the order of morpheme acquisition. Language learning: a journal of applied linguistics, v. 25, n.2, p. 237-243, 1975.

PERRENOUD, P. Avaliação:da excelência à regulação das aprendizagens. Porto Alegre: Artmédia, 1999.

PINKER, S. Learnability and Cognition: The Acquisition of Argument Structure. London: MIT Press, 1989.

PONTES, T. S. A avaliação na educação infantil, frente aos novos desafios. Belém: Unama, 2001. Disponível em: <http://www.nead.unama.br/ bibliotecavirtual/monografias/Avaliacao_educacao_infantil.pdf $>$. Acesso em: 13 mar. 2006.

POTTER, M. C. Remembering. In: OSHERSON, D. N.; SMITH, E. E. (Ed.). An invitation to cognitive science: thinking, v. 3, London: MIT Press, 19901995. Cap. 1, p. 3-32.

PRIETO, D.; GUTIERREZ, F. A mediação pedagógica - educação a distância alternativa. Campinas: Papirus, 1991.

RUMElHART, D.; McClELland, J. Parallel Distributed Processing: Exploratins in the Microstructure of Cognition. Cambridge: MIT Press, 1986.

RUMELHART, D. E.; SMOLENSKY, P; McClELLAND, J.; HINTON, G. E. Schemata and Sequential thought processes in PDP models. In: McClELLAND, J.; RUMELHART, D. E. (Ed.). Parallel Distributed Processing, v. 2. Cambridge: MIT Press, 1986. p. 7-57.

SACHS, J. S. Memory in reading and listening to discourse. Memory and Cognition, v. 2, p. 95-100, 1974.

SUTTON, J. Memory. In: Stanford Encyclopedia of Philosophy, 2004. Disponível em: <http://plato.stanford.edu/entries/memory\#3>. Acesso em: Mar./2006. 
VARELA, F. J.; THOMPSON, E.; ROSCH, E. The Embodied Mind, London, 1991.

VARELA, F. J. Connaître les Sciences Cognitives: Tendances et Perspectives. Paris: Éditions du Seuil, 1989.

WISEMAN, S.; NEISSER, U. Perceptual organization as determinant of visual recognition memory. American Journal of Psychology, v. 87, p. 675-681, 1974. 
$+1$ 